\title{
METHODOLOGICAL SUPPORT OF INSTRUCTING MATHEMATICS IN E-LEARNING ENVIRONMENT
}

\section{Rakhimov Kholmurot Abdullayevich}

Karshi Institute of Engineering and Economics, senior lecturer xolmurot.raximov@bk.ru

\author{
ABSTRACT \\ Keywords \\ Article Received: 18 October 2020, Revised: 3 November 2020, Accepted: 24 December 2020
}

\section{Introduction}

In world practice, special attention is paid to the development of pedagogical models for the implementation of the learning process in the elearning environment (distance), the identification of psychological and pedagogical features of teaching in e-learning, the selection of optimal learning options. This article discusses strategic guidelines for creating new math training programs for engineers due to the challenges of training appropriate personnel for our evolving society.

The article discusses professionally oriented teaching methods using computer technology in all areas of engineering, as well as in construction, mining and exploration, within the concept of a competent approach to the formation of senior, middle and lower engineers familiar with computer technology to solve problems.

1. Computer mathematics systems, their structure, functions and main characteristics One of the priorities in the development of engineering and education in the modern world is the use of computer technology.

2. Creating an e-course in mathematics, with the help of this e-course students can be offered lectures on mathematics, examples and problems for practical work, tests and logic puzzles. Taking this objective factor into account requires institutes to train high, middle and lower level engineers who are familiar with computer technology to solve problems in all areas of engineering, mining, prospecting.
In turn, today the teachers of the institute are required not only to be able to teach using the classical forms of teaching, but also to create and master new methods of learning sciences using computers and computer technology.

In developed countries of the world, the attention to mathematics is extremely high. In this area, mathematics has been identified in our country as one of the priorities for the development of science in 2020.

Over the past period, a number of systematic measures are planned to bring mathematics science and education to a new level: the Ministry of Public Education and the Ministry of Higher and Secondary Special Education through distance learning in specialized schools with the involvement of highly qualified professors of the Institute and higher education institutions measures are being taken to conduct classes.

Improving the teaching of mathematics to teachers, taking into account the following: the introduction of methods of teaching independent work; teaching the active use of multimedia and information technology in the classroom, increasing the weight of practical training. Introduction of a new subject "Computer Mathematical Systems" in the field of bachelor's degree in engineering. Creation of a separate universal textbook in mathematics for engineering, technical sciences, natural sciences, humanities.

Preparation of educational literature on the basis of animations, graphic materials on the basis of 
modern information technologies in mathematics is a topical issue.

Computer mathematical systems are a new branch of mathematics that has emerged at the intersection of classical mathematics and computer science. It emerged at the beginning of the new century and is associated with the success of introducing personal computers (PCs) into the practice of solving mathematical problems. The main tool of computer mathematics was computer mathematics systems (PCM).

They allow the use of mathematical methods without the order of programming, and thus create a favorable environment for specialists in all areas of any engineering, mining, prospecting.

We found that distance learning of mathematics in technical higher education institutions is the interaction of distance mathematics teacher and students, which is carried out with the help of information and communication technologies and allows to implement the established educational goals, objectives, pedagogical methods, distance learning methods.

Methodological system of teaching higher mathematics in technical higher education institutions in engineering specialties with traditional forms of education.

The following components can be distinguished in the structure of the methodical system, taking into account the influence of external factors and the activities of educational subjects (teacher, student) with the traditional forms of teaching higher mathematics (full-time, part-time). organizational forms and control, monitoring, etc.

Let us describe the components of the methodological system of mathematical education in traditional forms of education (full-time, parttime).

The objectives of teaching mathematics in technical higher education institutions we have presented above are combined and divided into three groups: theoretical and practical, logical and algorithmic, which we will consider in detail.

The first group of objectives includes the basics of mathematical apparatus (definition, theorem) required to solve theoretical and practical problems.

The second group of objectives includes: developing logical and algorithmic thinking skills, developing the ability to study applied mathematical literature independently, and raising the general level of mathematical culture.

The practical goals of mathematics education in technical higher education institutions include the development of the ability to model real-world processes, the development of research methods, and the solution of mathematically formalized problems.

The third group of objectives is as follows: The objectives of teaching mathematics in technical higher education institutions are directly related to practice, including the activities of the teacher and the student, as well as the content of mathematics education.

Teaching methods are methods of realizing the purpose and content of teaching mathematics in technical higher education institutions.

The mathematical structure of the subject is developed mainly through induction, deduction, and generalization, and the teacher-student relationship is manifested through repetition, heuristics, and research. The following teaching methods can be distinguished by the nature of the organization of educational activities and material content: inductive-reproductive, inductiveheuristic, inductive-research, deductivereproductive, deductive-heuristic, deductiveresearch, generalized-reproductive, generalizedheuristic, generalized research.

GI Sarantsev explains these teaching methods as follows. The essence of the inductive-reproductive method is the creation by the teacher of a situation in which the student repeats the concept, theorem, methods of activity, heuristics in the process of considering certain works.

The deductive-reproductive method involves the repetition of certain situations in the process of solving problems in which the general situation is used.

The goal is achieved by repeating the facts learned in a generalized-reproductive way. Or the skillful 
performance of any action from the elements is done in the process of assimilating its components and aggregates.

The deductive-heuristic method is to determine the specific features of the fact in considering this general case.

Heuristic generalization means that the student creates a situation in which the student comes to generalize independently (or with the help of the teacher).

The essence of the inductive research method is to study different phenomena by studying their specific manifestations.

The essence of the method of deductive research is to organize the research through the deductive development of the teaching material.

The training methods we present above are done using special training tools. A learning tool is an object that is needed to organize the learning process. The structure of the objects distinguishes between material and ideal teaching aids;

- textbooks - these are textbooks and manuals, tables, models, media, computers, teaching and technical aids, room laboratory equipment, furniture, microclimate, class schedule and more.

- an ideal study guide is a set of previously acquired knowledge and skills that teachers and students use to learn a new topic.

The Russian teacher and psychologist L.S. Vygotsky (1896-1914) distinguished the following means for teaching: speech, writing, symbols, drawings, diagrams, etc .; it is clear that in our view the tools for educating today's developed society can be supplemented with audio and video, multimedia and software tools to the above.

We recommend the creation of ETVs designed for the most common standard hardware and software platforms and information technology among the e-learning tools available during this study. Several software tools and methodological guidelines have been developed.

The main components of the methodological system of teaching mathematics in e-learning environment in technical higher education institutions have been identified.

The main components of the methodological system of distance learning of mathematics in technical higher education institutions are almost identical to the components of the methodological system of traditional forms of education, but some features have been studied.

The methodology of teaching mathematics in technical higher education institutions means the orderly methods of interaction between the teacher and the student aimed at achieving the learning objectives.

Electronic means of mathematics in technical higher education institutions include: printed materials, audio, video media; - electronic textbooks, curricula, computer tests and knowledge management, the latest multimedia tools; video conferencing through audio channels, video channels and computer networks.

GeoGebra is a multi-functional platform math program that becomes a good helper for everyone in reading or working by performing various mathematical operations.

This program combines geometry and algebra, building tables, statistical and arithmetic operations, and many other topics. Moreover, all of these sections are dynamically connected to each other in one set and are fully synchronized. Use equations, control coordinate grids, build graphs in 2D or 3D modes, and more.

With the help of the program you can not only perform the necessary mathematical operations, but also create interactive videos for video hosting, posting on sites necessary for the preparation of training manuals.

However, everything is created in an intuitive interface that even an ordinary reader can master. Thus, learning a function and its derivatives using GeoGebra becomes an easy and fun process, allowing you to easily understand the principles of basic operations.

1-Example. $y=\sin 2 x+\cos 3 x \quad$ Consider the function: 


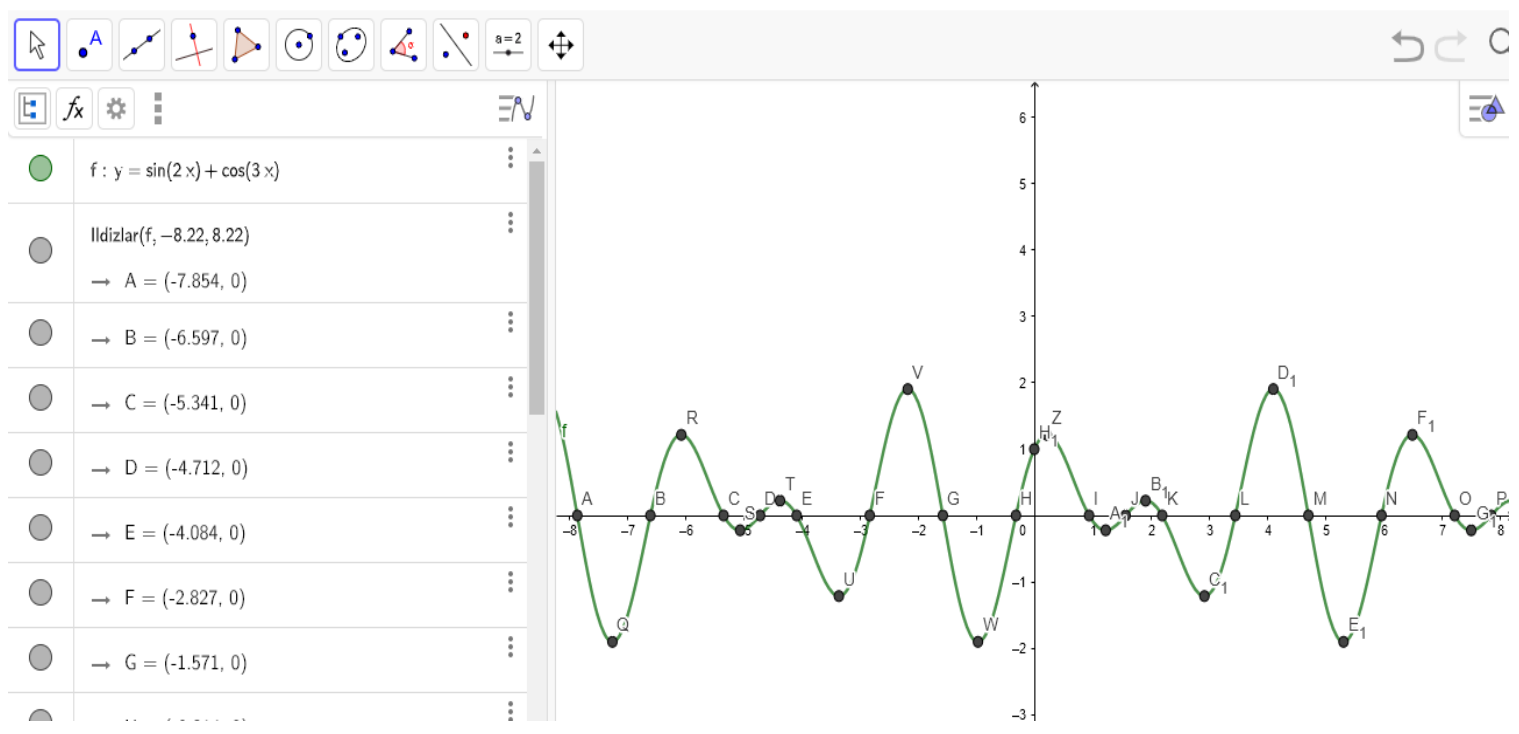

Key Features of the Application: The relationship between a function and its first two derivatives is illustrated using the simplest function example.
The graphs of the function and its first and second derivatives are defined accordingly.

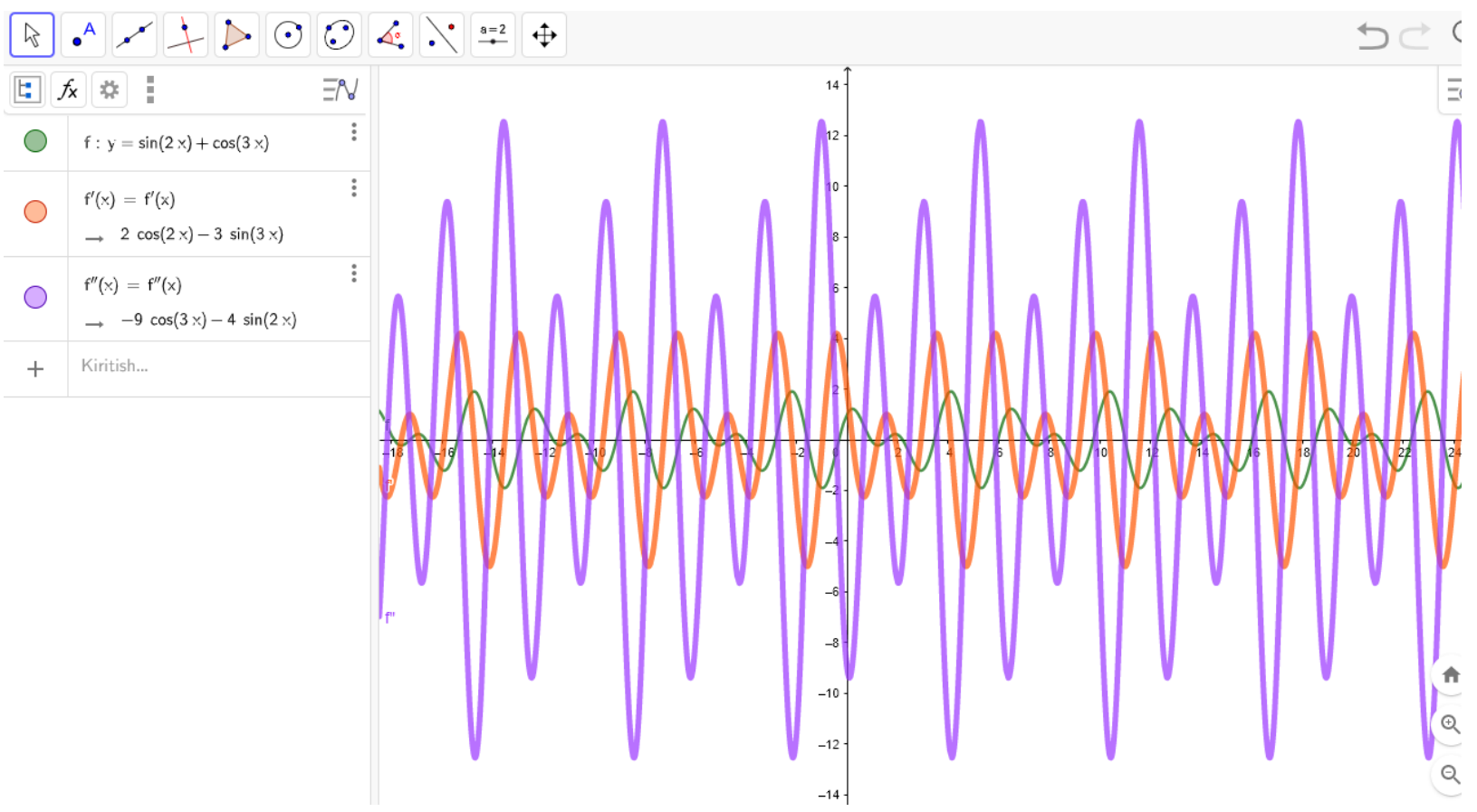

Draw given functions, create different 2D and 3D shapes (circle, ellipse, parabola, torus, cone, etc.). Example $3 \mathrm{y}=\mathrm{e}^{\wedge}(1 / \sqrt{\mathrm{x}})$. It can be difficult for students to draw and derive a graph of a function, but it will be easier for us if the GeoGebra program helps us. 


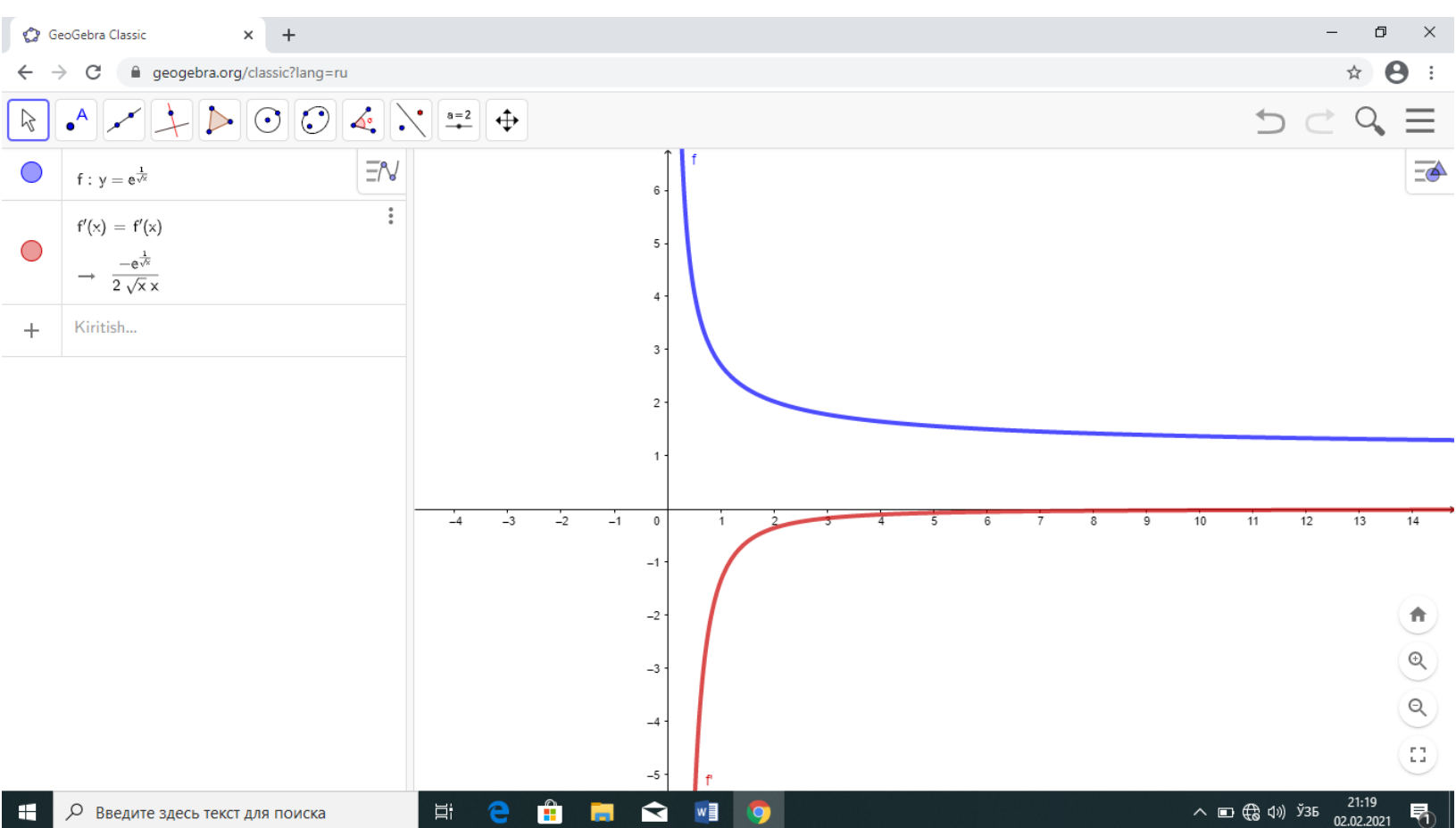

4-example. $x^{\wedge} 2+y^{\wedge} 2-z^{\wedge} 2=1$. We will see the problem of surface imaging using e-learning resources.

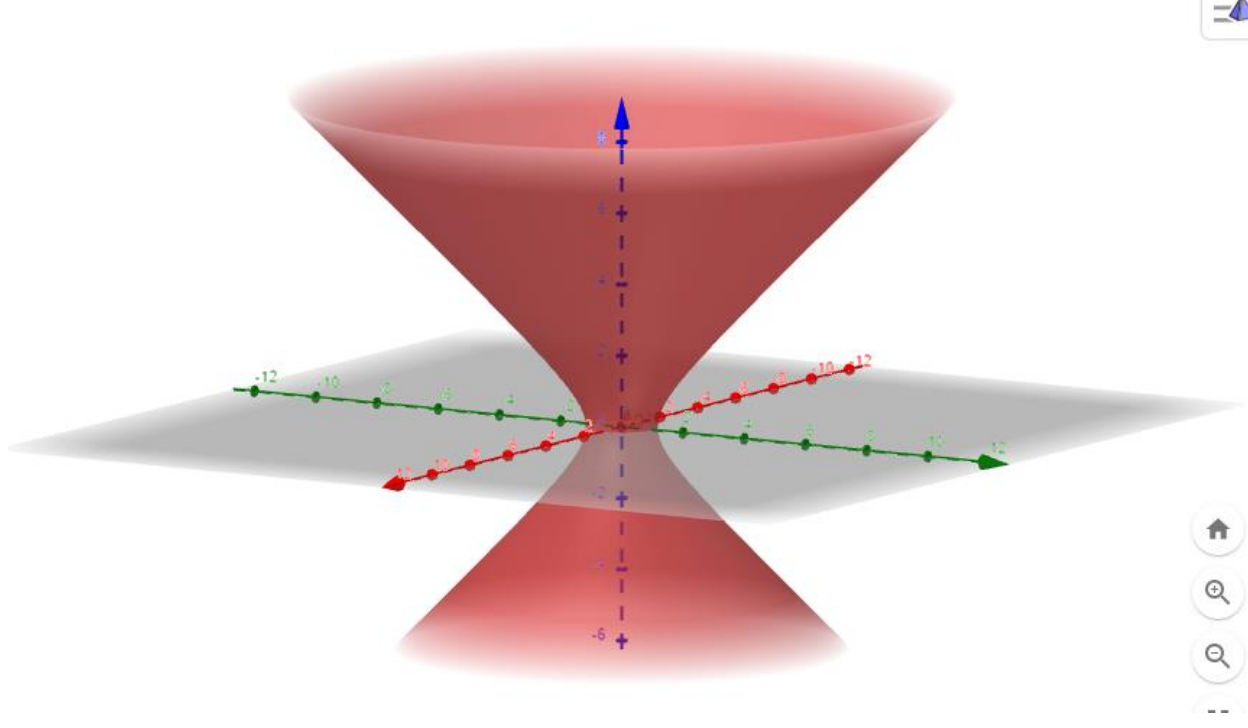

Computer graphics is an indispensable additional tool for imagination and mastery. The visual representation of complex three-dimensional surfaces poses great difficulties in studying the functions of two variables. the system also solves this problem by creating a visual spatial representation of mathematical expressions in two variables .At the same time, the feature of the system to rotate the graph and correct its arbitrary state allows a comprehensive and detailed study of the pattern described by the function. 3. A mathematical article based on the GeoGebra system can be considered as the final stage of teaching the science of mathematics based on the GeoGebrae system in the system of higher mathematics learning after the traditional study. In today's rapidly evolving information age, online platforms and online course platforms are proliferating and opportunities are increasing, including Udemy, Codecademy, Coursera, Skillshare, Edx, Pluralsight, Future Learn and Moodle's best online platforms, as well as LearnWorlds, Thinkific, Teachable, Kaji An example is online course platforms such as Podia. 
Online platforms have become a very fastgrowing industry during the quarantine period since the advent of Covid-19 in all states.

This epidemiological situation is supporting the online learning process for those who aim to both read and teach in the current era, helping them to teach online.

There are many online learning and course platforms that allow you to learn or create, sell online courses. This is a great opportunity for online teachers, coaches and students. However, it is a bit difficult to choose the best and most convenient online learning platform out of the many options available. The reason is that each online platform is aware of its offerings with opportunities and conveniences that do not lag behind each other in accordance with the requirements of today's market economy.

We will also learn about the capabilities of LearnWorlds, one of the online course platforms, and create our own online course platform.

LearnWorlds is a cloud-based platform that is offered to everyone as an individual solution that offers the opportunity to create your own online academy while creating unique, interactive and social learning experiences.

This platform brings together everything you need, while also making the process of creating online courses easier and more affordable. On top of that, it's designed to provide you with the right marketing tools to help you advertise and sell online courses.

\section{Conveniences:}

- Courses are very easy to set up and create and have a 30-day free trial period.

No technical skills are required to use it.

It comes with built-in authoring skills.

- It offers a modern and customizable course player.

It suggests the state of the art website manufacturer.

- It has built-in e-commerce, marketing and affiliate features.

- It includes a variety of learning tools and assessment mechanisms

It offers a robust system of conditions.

It comes with an internal online community and discussion.

Supports SCORM and HTML5 files.

\section{Disadvantages:}

It has limited gamification capabilities (symbols only).

- Does not support TinCan.

It offers limited opportunities for email marketing. LearnWorlds also provides website, page and zone templates, fully customizable branding, control who sees which zones / pages, and manages the user's navigation experience, as well as the best website creator.

Below we have created the platform https://raximov-xolmurot-

matematika.learnworlds.com/ on the basis of the LearnWorlds platform and an online course on Probability Theory and Mathematical Statistics on this platform.

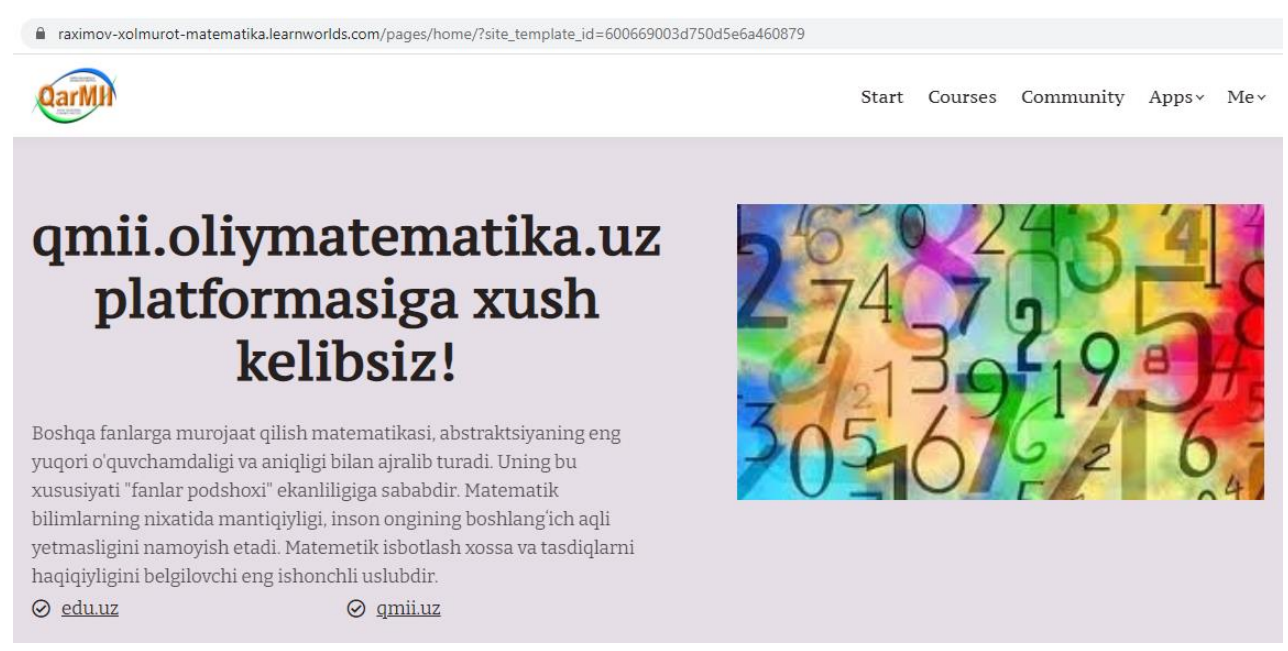




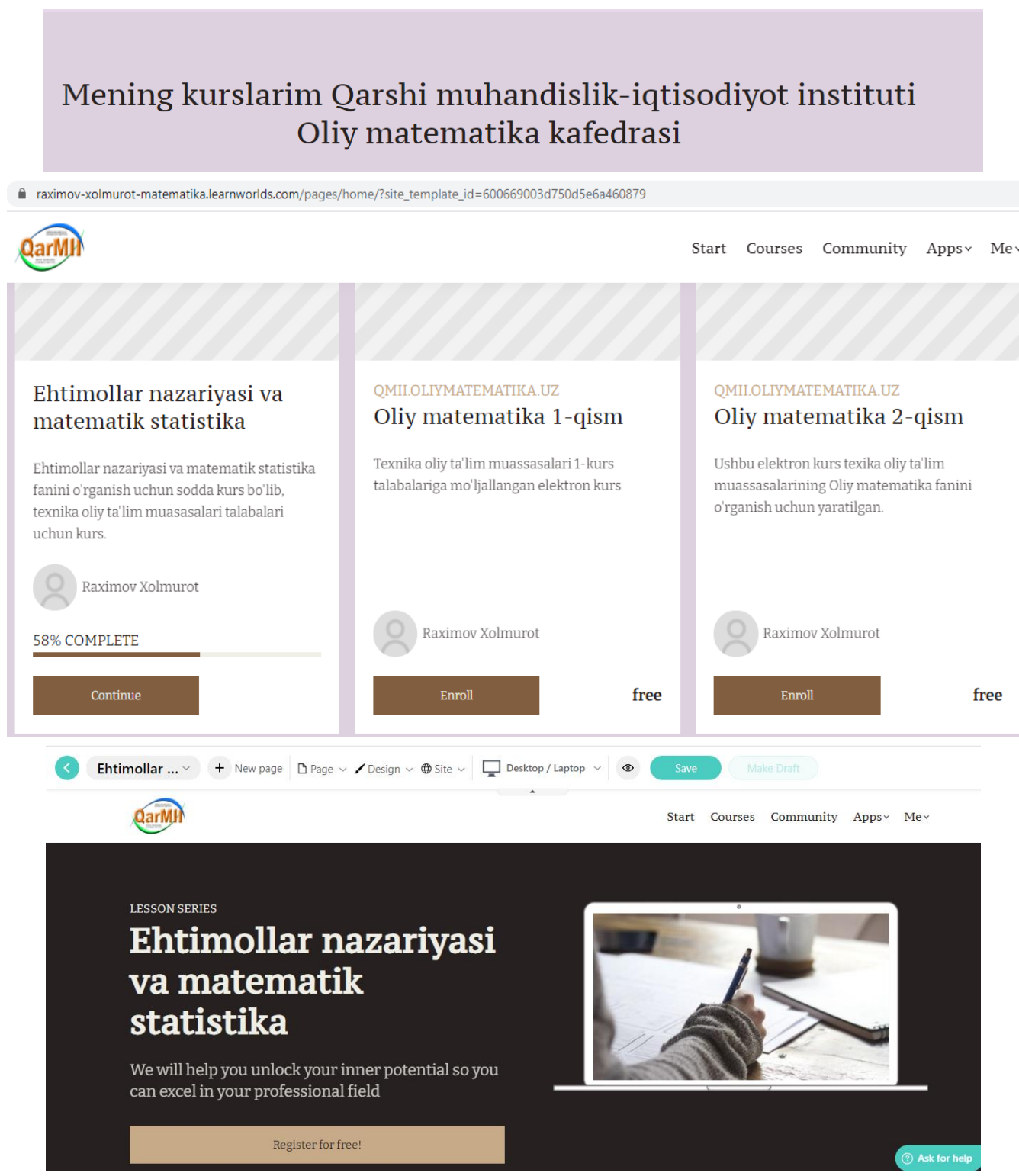

The scientific significance of the results of the study is the identification of pedagogical conditions that affect the e-learning environment in the future development of future engineers; high opportunities for students to study online; explained by the availability of modern software tools in the e-learning environment.

Summarizing the results of the research, the creation and use of electronic resources in the elearning environment in the teaching of mathematics, as in other disciplines, serves to increase the effectiveness of teaching teachers.

\section{References}

[1] Андреев A. А. Средства новых информационных технологий в образовании: систематизация и тенденции www.psychologyandeducation.net развития [Текст] / А.А. Андреев - М.: ВУ, 2011. - $153 \mathrm{c}$.

[2] Блинова Т. Л., Наймушина К. Ю. Создание персонального вебсайта педагога // Актуальные вопросы преподавания математики, информатики и информационных технологий [Электронный peсурс] : межвузовский сборник научных работ / Урал. гос. пед. ун-т ; науч. ред. Л. В. Сардак. Екатеринбург: 2019. - С. 15-22.

[3] https://www.geogebra.org/classic.lang.ru интернет сайти.

[4] https://raximov-xolmurotmatematika.learnworlds.com/author/dashboar d интернет сайти. 